\title{
Determinants of change in subtropical tree diameter growth with ontogenetic stage
}

\author{
Yong Shen $\cdot$ Louis S. Santiago $\cdot$ Hao Shen $\cdot$ Lei Ma • \\ Juyu Lian $\cdot$ Honglin Cao $\cdot$ Huanping Lu $\cdot$ Wanhui Ye
}

Received: 4 November 2013 / Accepted: 24 May 2014 / Published online: 18 June 2014

(C) Springer-Verlag Berlin Heidelberg 2014

\begin{abstract}
We evaluated the degree to which relative growth rate (RGR) of saplings and large trees is related to seven functional traits that describe physiological behavior and soil environmental factors related to topography and fertility for 57 subtropical tree species in Dinghushan, China. The mean values of functional traits and soil environmental factors for each species that were related to RGR varied with ontogenetic stage. Sapling RGR showed greater relationships with functional traits than large-tree RGR, whereas large-tree RGR was more associated with soil environment than was sapling RGR. The strongest single predictors of RGR were wood density for saplings and slope aspect for large trees. The stepwise regression model for large trees accounted for a larger proportion of variability $\left(R^{2}=0.95\right)$ in RGR than the model for saplings $\left(R^{2}=0.55\right)$. Functional diversity analysis revealed that the process of habitat filtering likely contributes to the
\end{abstract}

Communicated by Ylo Niinemets.

Y. Shen $\cdot$ H. Shen $\cdot$ L. Ma $\cdot$ J. Lian $\cdot$ H. Cao $\cdot$ H. Lu $\cdot$ W. Ye $(\bowtie)$ Key Laboratory of Vegetation Restoration and Management of Degraded Ecosystems, South China Botanical Garden, Chinese Academy of Sciences, Guangzhou 510650,

People's Republic of China

e-mail:why@scib.ac.cn

Y. Shen $\cdot$ L. Ma $\cdot$ H. Lu

University of Chinese Academy of Sciences, Beijing 10049,

People's Republic of China

L. S. Santiago

Botany and Plant Sciences Department, University of California, Riverside, CA 92521, USA

L. S. Santiago

Smithsonian Tropical Research Institute Balboa, Ancon, Panama, Republic of Panama substantial changes in regulation of RGR as communities transition from saplings to large trees.

Keywords Relative growth rate $\cdot$ Soil nutrient availability $\cdot$ Specific leaf area $\cdot$ Topography . Wood density

\section{Introduction}

Tree growth plays a key role in tropical forests because it forms the basis of many ecosystem processes (Clark et al. 2001; Enquist et al. 2007). Without a proper understanding of the determinants of tree growth, our understanding of forest dynamics and ecosystem function is limited. Determinants of tree growth are complex and related to many environmental factors, including topography (Tsujino et al. 2006), water availability (Condit et al. 1995) and nutrient limitation (Fisher et al. 2013; Santiago et al. 2012; Wright et al. 2011). However, species-based factors, especially the intrinsic growth capacities and functional traits of species, also regulate tree growth (Martínez-Vilalta et al. 2010; Poorter et al. 2008; Sterck et al. 2011). There is additional evidence that species' traits or environmental factors may shift in importance in different ontogenetic stages. Recent work in tropical forests illustrates that interspecific traitgrowth rate relationships tend to be stronger for small trees than for large trees (McMahon et al. 2011; Poorter et al. 2008; Wright et al. 2010), whereas environment-growth relationships tend to be stronger for large trees than for small trees (Webb and Peart 2000). Weaker relationships between growth and environmental factors in small trees compared to large trees suggest that seedling communities often contain species that are not well suited to a site. Thus in tropical forests, seedlings appear to suffer high mortality 
rates leading to a "habitat filtering" process that results in increasing relationships between growth and environmental factors in large trees (Webb and Peart 2000). We tested the relative effects of trait and environment on growth for saplings and trees of 57 subtropical tree species in the Dinghushan forest dynamics plot in Southern China, to determine which plant and environmental factors govern growth and how this changes with ontogeny.

Numerous studies have documented tropical tree growth in response to environmental factors. There is abundant evidence indicating that light is a major environmental factor that determines tree growth, biomass allocation and functional traits (Kohyama 1987; Kohyama and Grubb 1994; Delagrange et al. 2004). In fact, functional and growth traits change depending on light availability and ontogeny, and the changes are not necessarily coordinated among traits, making it difficult to distinguish the effects of traits on growth with respect to this extremely heterogeneous environmental factor. Beyond light, belowground resources are thought to be major limiting environmental factors for growth because tropical forests have climates that are favorable for plant growth. However, heterogeneous environments can result in differential water and nutrient availability, even at small $(<1 \mathrm{~m})$ scales (Bellingham and Tanner 2000). Variation in nutrient availability and soil properties is directly related to plant performance (Ehrenfeld et al. 2005) and important nutrient cycling processes related to plant performance are known to vary along environmental gradients (Santiago et al. 2005; Vitousek 2004). Growth and mortality rates of trees are correlated with soil properties across different soil types (Palmiotto et al. 2004; Russo et al. 2005), and under experimental nutrient addition (Santiago et al. 2012; Wright et al. 2011). Furthermore, altitude and convexity play important roles in controlling species richness and composition due to effects on water availability and other soil properties (Harms et al. 2001; Legendre et al. 2009). Additionally, topography often drives the spatial variation in water availability at local scales (Comita and Engelbrecht 2009), with water-demanding species preferentially associated with the slopes due to greater water availability (Harms et al. 2001). Thus, many of the environmental factors controlling tropical tree growth are associated with well-characterized measures of belowground resource availability.

Other determinants of plant growth include species-specific life history characteristics and growth capacities which are usually represented by functional traits, the relatively simple-to-measure phenotypic attributes of species that describe more complex physiological performance (Poorter et al. 2008; Violle et al. 2007). Although the idea of traitbased community ecology is not new (Grime 1977), only recently have ecologists agreed on suites of traits that reflect axes of ecological strategy variation (Westoby et al. 2002).
Some of the leading dimensions that have emerged include suites of traits related to the leaf economics spectrum (Reich et al. 1997; Wright et al. 2004), maximum plant height (Falster and Westoby 2005; Santiago and Wright 2007; Westoby et al. 2002), tissue density, water transport capacity and drought resistance in woody stems (Martínez-Vilalta et al. 2002; Pockman and Sperry 2000; Santiago et al. 2004b) and seed size and reproductive output (Moles et al. 2005; Westoby et al. 2002). Thus complex physiological, structural and life history attributes can be represented by simpler functional traits for comparison of many species.

We evaluated the degree to which growth of saplings and trees is related to plant functional traits versus soil topography and fertility for 57 subtropical tree species. Our main questions were:

1. Which functional traits and environmental factors are related to the growth of subtropical tree species in Dinghushan, China?

2. How do relationships between growth, functional traits and environmental factors vary among plant ontogenetic stages?

3. Is there evidence for habitat filtering between sapling and tree stages?

Because the plant traits and environmental factors that we measured are well-established regulators of plant performance, we hypothesized that all of them had the potential to influence growth. We also hypothesized that relationships between growth and plant traits would be stronger for saplings than trees, but that relationships between growth and environmental factors would be stronger for trees than saplings, consistent with habitat filtering.

\section{Materials and methods}

Study site and census data

We conducted this study in the Center for Tropical Forest Science 20-ha Dinghushan (DHS) forest dynamics plot located within the Dinghushan Natural Reserve $(1,155$ ha), Guangdong Province, China $\left(23^{\circ} 09^{\prime} 21^{\prime \prime}-23^{\circ} 11^{\prime} 30^{\prime \prime} \mathrm{N}\right.$, $\left.112^{\circ} 30^{\prime} 39^{\prime \prime}-112^{\circ} 33^{\prime} 41^{\prime \prime} \mathrm{E}\right)$. The mean annual temperature and precipitation are $20.9{ }^{\circ} \mathrm{C}$ and $1,927 \mathrm{~mm}$, respectively, and mean relative humidity is $85 \%$. The altitude of the plot ranges from 230 to $470 \mathrm{~m}$, and the landform is highly complex, with steep slopes. The soil is composed mainly of lateritic red and mountain yellow brown soil. The forest at the site has been conserved for $>400$ years by monks at the Buddhist Temple near the site. The only anthropogenic disturbance to the site since then has been several small graves dug within flat areas of the plot $>100$ years ago. 
All stems within the 20-ha plot with a diameter at breast height $(\mathrm{DBH}) \geq 1 \mathrm{~cm}$ were measured, mapped, and tagged when the plot was established in 2004-2005 (Ye et al. 2008). A total of 178 species and 61,125 individuals were recorded in the second census in 2010 . We divided individuals into two ontogenetic stages based on $\mathrm{DBH}$, which included saplings (1-5 cm; 44,709 individuals) and large trees $(10-50 \mathrm{~cm} ; 10,641$ individuals). To limit sapling analyses to sterile individuals, we excluded trees with DBH $>5$ and $<10 \mathrm{~cm}$ (Wright et al. 2010). Relative growth rate of stem diameter (RGR; $\mathrm{cm} \mathrm{cm}^{-1}$ year $^{-1}$ ) was calculated as $\left(\log \left(\mathrm{DBH}_{\mathrm{t}}\right)-\log \left(\mathrm{DBH}_{\mathrm{o}}\right)\right) / t$, where $\mathrm{DBH}_{\mathrm{o}}$ and $\mathrm{DBH}_{\mathrm{t}}$ represent $\mathrm{DBH}$ at the first and last census, respectively (Poorter et al. 2008). Calculations of RGR were done only for species that had at least 20 individuals in each size class during the initial census (Poorter et al. 2008; Shen et al. 2013), resulting in 57 and 29 species for saplings and large trees, respectively.

\section{Functional traits}

We measured seven functional traits associated with plant physiological performance to distinguish phenotypic attributes among species based on the standardized methods of Cornelissen et al. (2003). Leaves were collected from the six smallest and six largest individuals of each species. Leaf chlorophyll concentration $\left(\mathrm{Chl} ; \mathrm{g} \mathrm{m}^{-2}\right.$ ) was evaluated as the average of three points on each leaf by a portable chlorophyll meter (SPAD 502, Plus Chlorophyll Meter; Konica Minolta, USA), based on an established relationship with total chlorophyll (Loh et al. 2002). Leaf size $\left(S ; \mathrm{cm}^{2}\right)$ was determined using a scanner (CanoScan LiDE 700F), and image processing software (ImageJ version 1.43u; National Institute of Mental Health, Bethesda, MD). Leaf lamina thickness $(T ; \mathrm{mm})$ was measured twice on each side of the main vein at the widest part of each leaf using a micrometer and avoiding large secondary veins. After weighing for fresh mass, leaves were placed in an oven at $60{ }^{\circ} \mathrm{C}$ for at least $72 \mathrm{~h}$, and then re-weighed to determine dry mass. Specific leaf area (SLA; $\mathrm{cm}^{2} \mathrm{~g}^{-1}$ ) was determined by dividing $S$ by oven-dried mass. Leaf dry matter content (LDMC; $\mathrm{g} \mathrm{g}^{-1}$ ) was expressed as the ratio of leaf dry mass to leaf fresh mass.

Wood samples from outside of the plot were collected from six randomly chosen individuals of each species. An increment borer was used to extract a 1-cm-diameter core at $\sim 1.5-\mathrm{m}$ height on the main stem for trees larger than $6 \mathrm{~cm} \mathrm{DBH}$, but for smaller trees and shrubs, we collected 10-cm-long, 1-cm-diameter stem segments from terminal branches. Wood sample volume was quantified using water displacement (Cornelissen et al. 2003), and dry mass was determined after at least $96 \mathrm{~h}$ at $60{ }^{\circ} \mathrm{C}$.
Wood density $\left(\rho ; \mathrm{g} \mathrm{cm}^{-3}\right)$ was calculated as the ratio of dry mass to fresh volume. The maximum height $\left(H_{\max }\right.$; $\mathrm{m})$ normally obtained by each study species was obtained from the Flora of China (http://frps.plantphoto.cn). All functional traits of saplings and mature trees were averaged, resulting in one mean value of each trait for each species.

\section{Soil environment}

Topographical indices of habitat were measured as quadrat altitude $(\mathrm{m})$, convexity $(\mathrm{m})$, slope angle $\left(^{\circ}\right)$ and slope aspect $\left({ }^{\circ}\right)$. Altitude was measured in each $20 \times 20-\mathrm{m}$ quadrat within the 20-ha plot using an Electronic Total Station and averaging values from the four corners of each quadrat (Legendre et al. 2009). Convexity of each $20 \times 20$-m quadrat was calculated as the altitude of the focal plot minus the mean altitude of the eight $20 \times 20-\mathrm{m}$ quadrats around each focal plot. For the edge quadrat, convexity was the altitude of the center point minus the mean of its four corners. Slope angle is defined as the mean angular deviation from the horizontal of each of the four triangular planes formed by connecting three of the corners of each $20 \times 20-\mathrm{m}$ quadrat. Slope aspect is defined as the compass direction in which a slope faces (Legendre et al. 2009).

Soil-based indices of habitat were determined by sampling soils in a $30-\mathrm{m}$ grid of points. Each alternate grid point was paired with two additional sample points at 2, 5 , or $15 \mathrm{~m}$ in a random compass direction from the grid to capture fine-scale variation in soil properties for a total of 710 samples (Lin et al. 2013). At each point, we collected $500 \mathrm{~g}$ topsoil $(0-10 \mathrm{~cm}$ depth) and analyzed eight soil properties: total $\mathrm{N}\left(\mathrm{TN} ; \mathrm{mg} \mathrm{g}^{-1}\right.$ ), available $\mathrm{N}$ (AN; $\mathrm{mg} \mathrm{g}^{-1}$ ), total P (TP; $\mathrm{mg} \mathrm{g}^{-1}$ ), available P (AP; $\mathrm{mg} \mathrm{g}^{-1}$ ), total $\mathrm{K}\left(\mathrm{TK} ; \mathrm{mg} \mathrm{g}^{-1}\right)$, available $\mathrm{K}\left(\mathrm{AK} ; \mathrm{mg} \mathrm{g}^{-1}\right)$, organic matter $\left(\mathrm{OM} ; \mathrm{mg} \mathrm{g}^{-1}\right)$ and soil $\mathrm{pH}$. Soil values for each $20 \times 20$-m quadrat were calculated using kriging methods. Each individual tree was assigned the soil environmental variables of its $20 \times 20$-m quadrat, with means calculated for saplings and large trees of each species.

\section{Data analysis}

All variables were checked for normality and transformed logarithmically when required (Table 1). Pearson correlation analysis was used to test for the association between pairs of functional traits, and relationships between functional traits, environmental factors and RGR. To test whether different ontogenetic stages showed similar functional trait-RGR or environment-RGR relationships, we used analysis of covariance (ANCOVA) with RGR as 
Table 1 Pearson correlation coefficients for relationships between relative growth rates (RGR) and topographical and soil characteristics, and functional traits for saplings $(1 \mathrm{~cm} \leq$ diameter $\leq 5 \mathrm{~cm})$ and large trees $(10 \mathrm{~cm} \leq$ diameter $\leq 50 \mathrm{~cm})$ from a 20 -ha forest dynamics plot in Dinghushan, China

\begin{tabular}{|c|c|c|c|}
\hline & Model & Saplings & Large trees \\
\hline \multirow[t]{7}{*}{ Functional traits } & $\log (\mathrm{RGR})-\mathrm{Chl}$ & 0.003 & 0.32 \\
\hline & $\log (\mathrm{RGR})-\log (S)$ & $0.48 * * *$ & 0.20 \\
\hline & $\log (\mathrm{RGR})-\mathrm{LDMC}$ & 0.07 & -0.09 \\
\hline & $\log ($ RGR $)-\log ($ SLA $)$ & 0.22 & 0.18 \\
\hline & $\log ($ RGR $)-\log (T)$ & -0.16 & -0.13 \\
\hline & $\log ($ RGR $)-\log \left(H_{\max }\right)$ & $0.38 * *$ & 0.30 \\
\hline & $\log (\mathrm{RGR})-\rho$ & $-0.49 * * *$ & -0.27 \\
\hline \multirow[t]{4}{*}{ Topography } & $\log ($ RGR $)$-Alt & -0.20 & -0.06 \\
\hline & $\log (\mathrm{RGR})-\mathrm{Asp}$ & 0.14 & $0.63 * * *$ \\
\hline & $\log (\mathrm{RGR})-$ Con & $-0.40 * *$ & 0.15 \\
\hline & $\log ($ RGR)-Slo & 0.14 & 0.30 \\
\hline \multirow[t]{8}{*}{ Soil } & $\log (\mathrm{RGR})-\mathrm{pH}$ & -0.20 & -0.26 \\
\hline & $\log (\mathrm{RGR})-\mathrm{OM}$ & 0.10 & $0.45^{*}$ \\
\hline & $\log (\mathrm{RGR})-\mathrm{TK}$ & $0.37 * *$ & 0.26 \\
\hline & $\log (\mathrm{RGR})-\mathrm{AK}$ & $0.28 *$ & $0.40 *$ \\
\hline & $\log (\mathrm{RGR})-\mathrm{TP}$ & -0.12 & $-0.39 *$ \\
\hline & $\log (\mathrm{RGR})-\mathrm{AP}$ & $0.28 *$ & 0.35 \\
\hline & $\log (\mathrm{RGR})-\mathrm{TN}$ & 0.24 & $0.40 *$ \\
\hline & $\log (\mathrm{RGR})-\mathrm{AN}$ & 0.25 & $0.40 *$ \\
\hline
\end{tabular}

Functional traits included are leaf chlorophyll concentration (Chl), leaf size $(S)$, leaf dry matter content (LDMC), specific leaf area (SLA), leaf thickness $(T)$, maximum height $\left(H_{\text {max }}\right)$ and wood density $(\rho)$

Alt, Altitude; Asp, slope aspect; Con, convexity; Slo, slope angle; $\mathrm{pH}$, soil $\mathrm{pH}$; OM, organic matter; TK, total $\mathrm{K}$; $\mathrm{AK}$, available $\mathrm{K}$; TP, total $\mathrm{P}$; AP, available $\mathrm{P}$; $\mathrm{TN}$, total $\mathrm{N}$; $\mathrm{AN}$, available $\mathrm{N}$

$* P<0.05, * * P<0.01, * * * P<0.001$

the dependent variable, functional traits or soil environmental factors as covariates, and ontogenetic stage as a grouping factor. A significant ontogenetic stage $\times$ covariate interaction would indicate that the slope of the functional trait-RGR or environment-RGR relationship differs among ontogenetic stages. When the interaction was insignificant, the analysis was repeated without the insignificant interaction term to determine whether the intercept of the functional trait-RGR or environmentRGR relationship differed among ontogenetic stages (Poorter et al. 2008). ANCOVA was conducted using the $\mathrm{HH}$ package in $\mathrm{R}(2.13 .2,2011)$. Stepwise multiple regressions including all variables were performed to evaluate relationships between RGR and combinations of functional traits and environmental factors. In order to determine the relative importance of each functional trait and environmental factor in different ontogenetic stages in the final regression models, we decomposed $R^{2}$ using hierarchical partitioning (Chevan and Sutherland 1991; Gromping 2006; Mac Nally 2002) in the relaimpo package in $\mathrm{R}(2.13 .2,2011)$.

To test for effects of habitat filtering, three indices of functional diversity (functional richness, functional evenness, and functional dispersion) were calculated for all traits except $H_{\max }$, which was not measured on site. Functional richness was defined as the volume of trait space occupied by species in the community (Mason et al. 2005; Villeger et al. 2008), estimated by calculating the convex hull volume, a construct from computational geometry (Cornwell et al. 2006). Functional evenness quantifies regularity of the distribution of abundance in the volume of trait space (Mason et al. 2005; Villeger et al. 2008). Functional dispersion quantifies the mean distance of individual species to the centroid of all species in the community (Laliberte and Legendre 2010). Functional evenness ranges from 0 to 1 , a high value denotes more regularity in the distribution of abundance in the volume of functional trait space (Carreno-Rocabado et al. 2012). Functional evenness and dispersion are independent from species richness, which allows comparison of quadrats and ontogenetic stages with different species richness without bias, and their independence from functional richness allows for testing of differences in functional evenness or dispersion with different functional richness values (Laliberte and Legendre 2010; Villeger et al. 2008). Co-occurring species tend to be functionally convergent under strong environmental filtering (Chalmandrier et al. 2013; Cornwell et al. 2006; Spasojevic and Suding 2012). We expected that functional similarity would increase from saplings to large trees. Functional diversity was calculated for the 92 most dominant species, which make up $95.5 \%$ of the cumulative community basal area in the DHS plot.

\section{Results}

Relationships between functional traits and RGR

Functional trait-RGR relationships for saplings differed from those of large trees. In saplings, $S$ and $H_{\max }$ had significant positive relationships with RGR (Table 1; Fig. 1), but $\rho$ was significantly negatively correlated with RGR. In large trees, none of the relationships between RGR and functional traits were significant.

\section{Relationships between environment and RGR}

Relationships between environment and RGR depended on ontogenetic stage. In saplings, RGR showed a 
Table 2 Stepwise multiple regressions relating $\mathrm{RGR}$, functional traits and environments for saplings $(1 \mathrm{~cm} \leq$ diameter $\leq 5 \mathrm{~cm})$ and large trees

$(10 \mathrm{~cm} \leq$ diameter $\leq 50 \mathrm{~cm})$ from a 20-ha forest dynamics plot in Dinghushan, China

$b$, Regression slopes; See

Table 1 for other abbreviations

$* P<0.05, * * P<0.01$,

$* * * P<0.001$

\begin{tabular}{|c|c|c|c|c|c|c|}
\hline & \multicolumn{3}{|l|}{ Saplings } & \multicolumn{3}{|l|}{ Large trees } \\
\hline & Variable & $b$ & $P$ & Variable & $b$ & $P$ \\
\hline \multirow[t]{5}{*}{ Functional traits } & Chl & 0.01 & * & Chl & 0.03 & $* * *$ \\
\hline & $\log (S)$ & 0.30 & $* *$ & $\log (S)$ & 0.24 & $* * *$ \\
\hline & LDMC & 2.50 & $* *$ & $\log (T)$ & -0.54 & $* * *$ \\
\hline & $\rho$ & -1.75 & $* *$ & $\log \left(H_{\max }\right)$ & 0.04 & $*$ \\
\hline & - & - & - & $\rho$ & -1.19 & $* * *$ \\
\hline \multirow[t]{4}{*}{ Topography } & - & - & - & Alt & 0.01 & $* *$ \\
\hline & - & - & - & Asp & 0.01 & $* *$ \\
\hline & - & - & - & Con & 0.17 & $* * *$ \\
\hline & - & - & - & Slo & -0.05 & $*$ \\
\hline \multirow[t]{6}{*}{ Soil } & $\mathrm{pH}$ & -16.67 & $* * *$ & $\mathrm{pH}$ & 17.83 & $* * *$ \\
\hline & TK & 4.39 & $* * *$ & TO & -0.09 & $* *$ \\
\hline & $\mathrm{AP}$ & -22.33 & $*$ & TK & 2.56 & $*$ \\
\hline & $\mathrm{TN}$ & -0.04 & $*$ & $\mathrm{TP}$ & -2.21 & $* * *$ \\
\hline & - & - & - & $\mathrm{TN}$ & 0.07 & $* * *$ \\
\hline & - & - & - & AN & -3.40 & $* * *$ \\
\hline$R^{2}$ & 0.55 & & & 0.95 & & \\
\hline
\end{tabular}
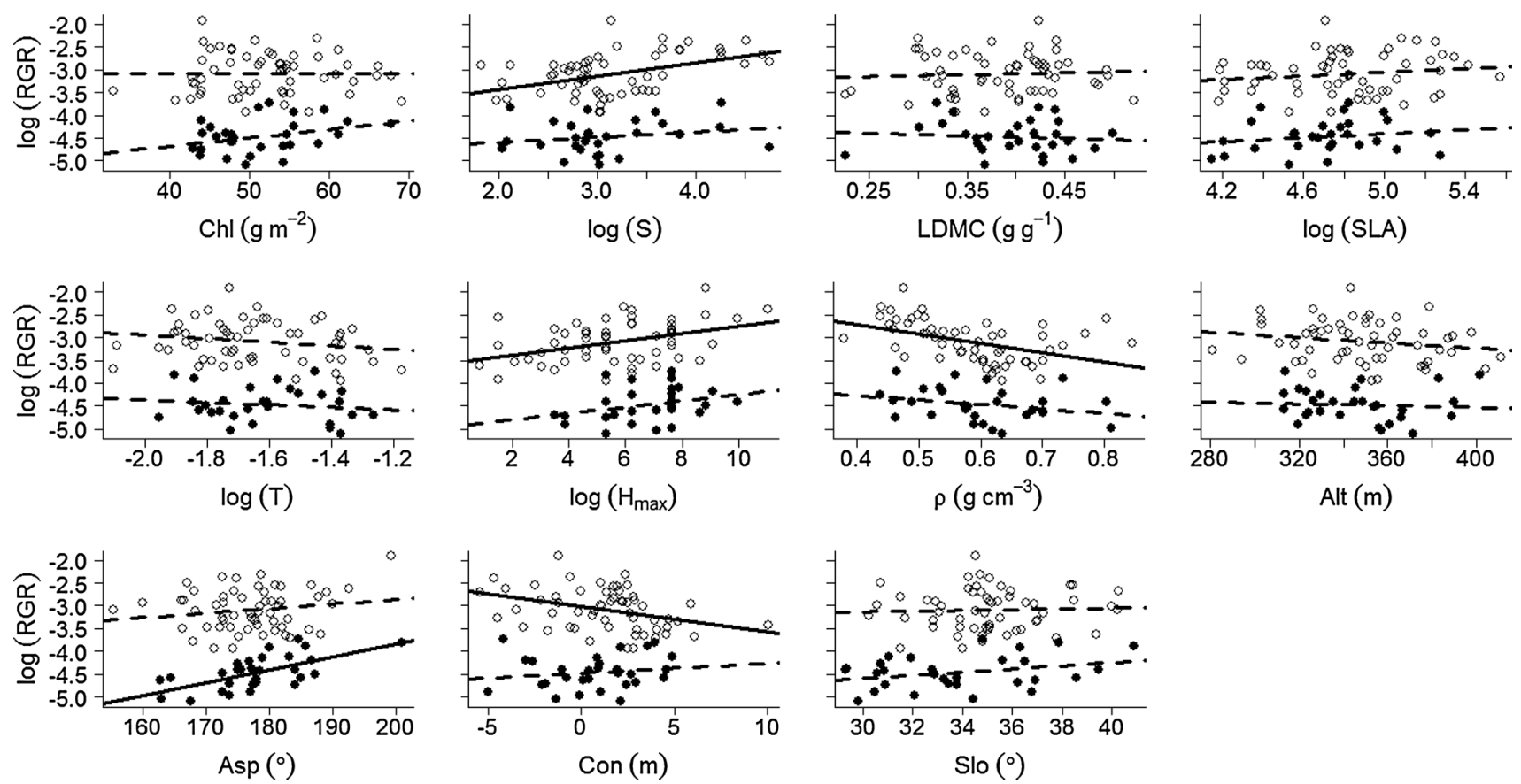

Fig. 1 Relative growth rate (RGR) versus functional traits and topography with ontogenetic stage as a covariate for subtropical tree species growing in the 20-ha forest dynamics plot in Dinghushan, China. Solid circles indicate large trees $(10 \leq$ diameter $\leq 50)$, whereas hollow circles indicate saplings $(1 \leq$ diameter $\leq 5)$. Significant interaction was found with convexity (Con; $P<0.05$ ), but intercepts differed

negative relationship with convexity (Table 1; Fig. 1), and had positive relationships with TK, AK and AP (Table 1; Fig. 2). For large trees, positive relationships

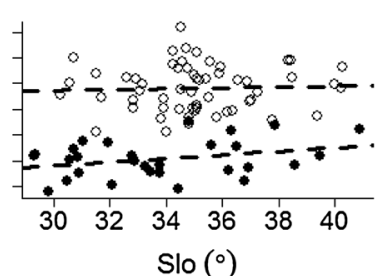

significantly for all of the relationships. Significant relationships are shown by solid lines, and insignificant relationships are shown by dashed lines. Chl, Leaf chlorophyll concentration; $S$, leaf size; LDMC, leaf dry matter content; SLA, specific leaf area; $T$, leaf thickness; $H_{\max }$, maximum height; Alt, altitude; Asp, slope aspect; Slo, slope angle. $* P<0.05, * * P<0.01, * * * P<0.001$

were observed between RGR and slope aspect, OM, AK, TN and AN, whereas RGR was negatively correlated with TP. 

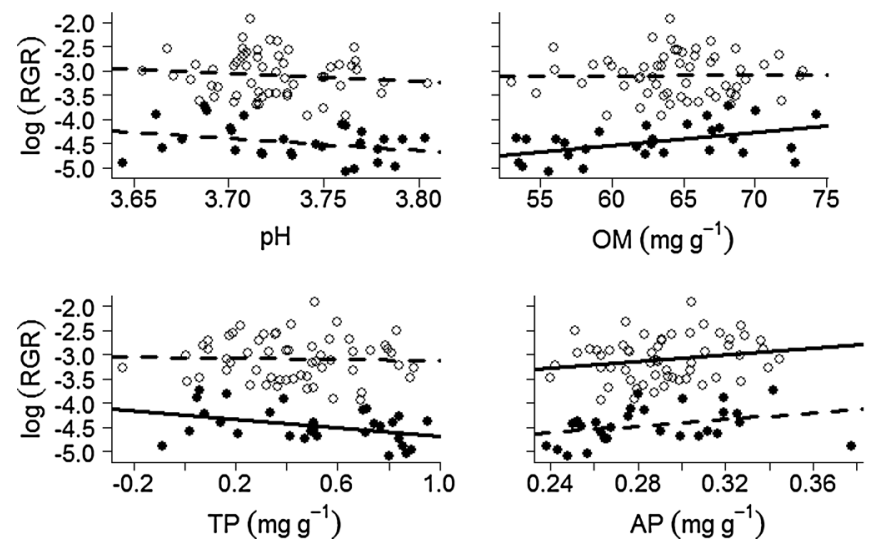

Fig. 2 RGR versus soil with ontogenetic stage as a covariate for subtropical tree species growing in the 20-ha forest dynamics plot in Dinghushan, China. Solid circles indicate large trees $(10 \leq$ diameter $\leq 50)$, whereas hollow circles indicate saplings $(1 \leq$ diameter $\leq 5$ ). No significant difference of slopes were observed, but

\section{Univariate regressions and ANCOVA}

The only significant interaction with ontogenetic stage as a covariate was found with convexity (Fig. 1), which had a negative relationship with RGR in saplings and a positive relationship with RGR in large trees. For other functional traits and environmental factors, analyses were performed again without the insignificant ontogenetic stage-covariate interactions, and ANCOVA showed that intercepts differed significantly among ontogenetic stages for all of the relationships (Figs. 1, 2).

Determinants of RGR and relative importance of functional traits and environment

The results of stepwise multiple regressions showed that significant variables in the two final models varied (Table 2). Only functional traits and soil properties, but not topographical factors, were significant in the final model for saplings. The model for large trees accounted for a larger proportion of variability $\left(R^{2}=0.95\right)$ in RGR than the model for saplings $\left(R^{2}=0.55\right)$.

When we decomposed the $R^{2}$ of the three models to find the best predictors of RGR, they were $\rho$ for saplings $\left(27.88 \%\right.$ of total $R^{2}$ ) and slope aspect for large trees (16.96\% of total $R^{2}$; Fig. 3). Functional traits were better predictors of RGR than soil environment for saplings $\left(60.44 \%\right.$ of total $R^{2}$ ), but this was not the case for large trees (33.55\% of total $R^{2}$; Fig. 3). Environmental factors contributed $66.45 \%$ of total $R^{2}$ to the model of large trees, indicating an ontogenetic shift in factors related to RGR.

All indices of functional diversity showed evidence of increasing functional similarity as tree communities develop from saplings to large trees, consistent with habitat
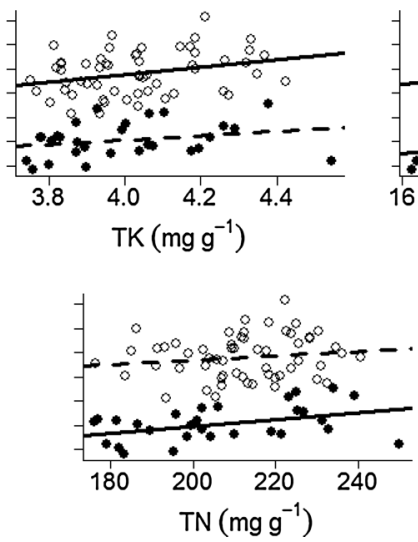
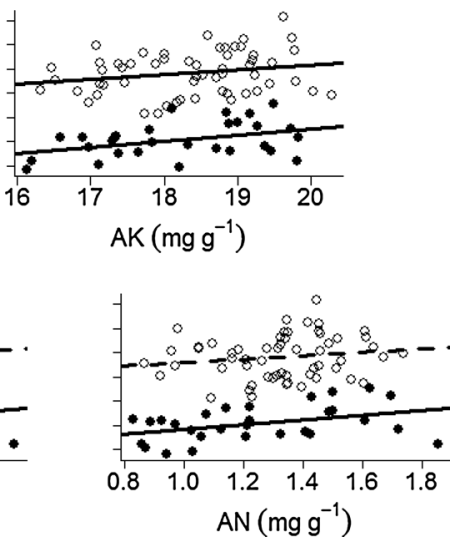

intercepts differed significantly for all of the relationships. Significant relationships are shown by solid lines, and insignificant relationships were shown by dashed lines. See Fig. 1 for abbreviations. ${ }^{*} P<0.05$, $* * P<0.01, * * * P<0.001$
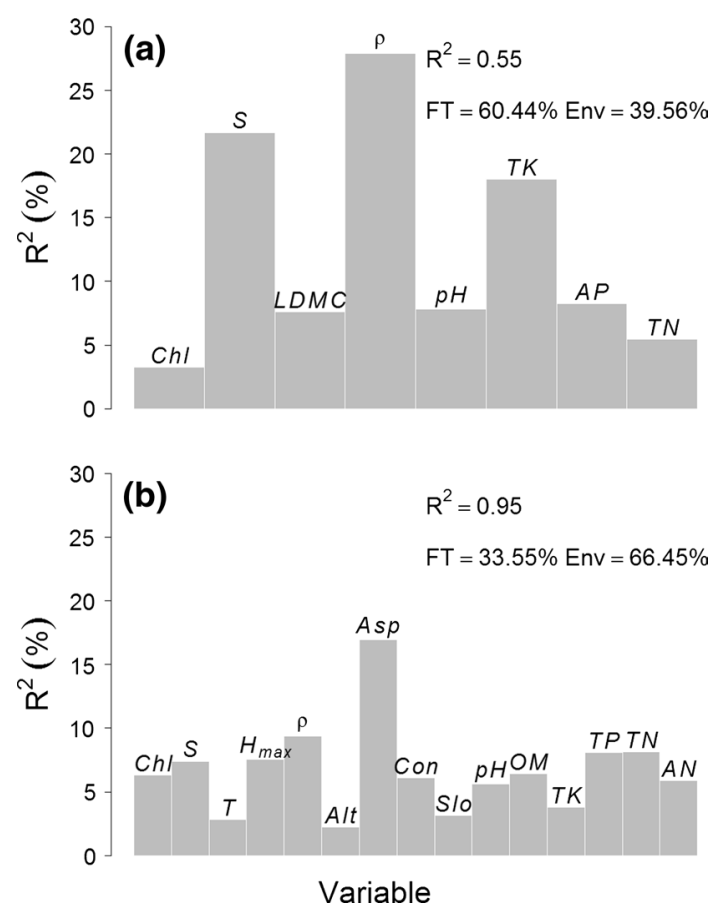

Fig. 3 Relative importance of each regressor in the final stepwise multiple regression models for a saplings $(1 \mathrm{~cm} \leq$ diameter $\leq 5 \mathrm{~cm})$ and $\mathbf{b}$ large trees $(10 \mathrm{~cm} \leq$ diameter $\leq 50 \mathrm{~cm})$, from the 20 -ha forest dynamics plot in Dinghushan, China. $R^{2}$ and the proportion of $R^{2}$ contributed by functional traits $(F T)$ and environments $(E n v)$ are shown. See Fig. 1 for other abbreviations

filtering. Functional richness was greater in saplings than in large trees for all six analyzed traits $(P<0.001$; Fig. 4a). Functional evenness was greater in large trees than in saplings for four out of six traits (Fig. 4b). Functional dispersion significantly decreased from saplings to large trees for all traits except for $T$ (Fig. 4c). All indices of functional 

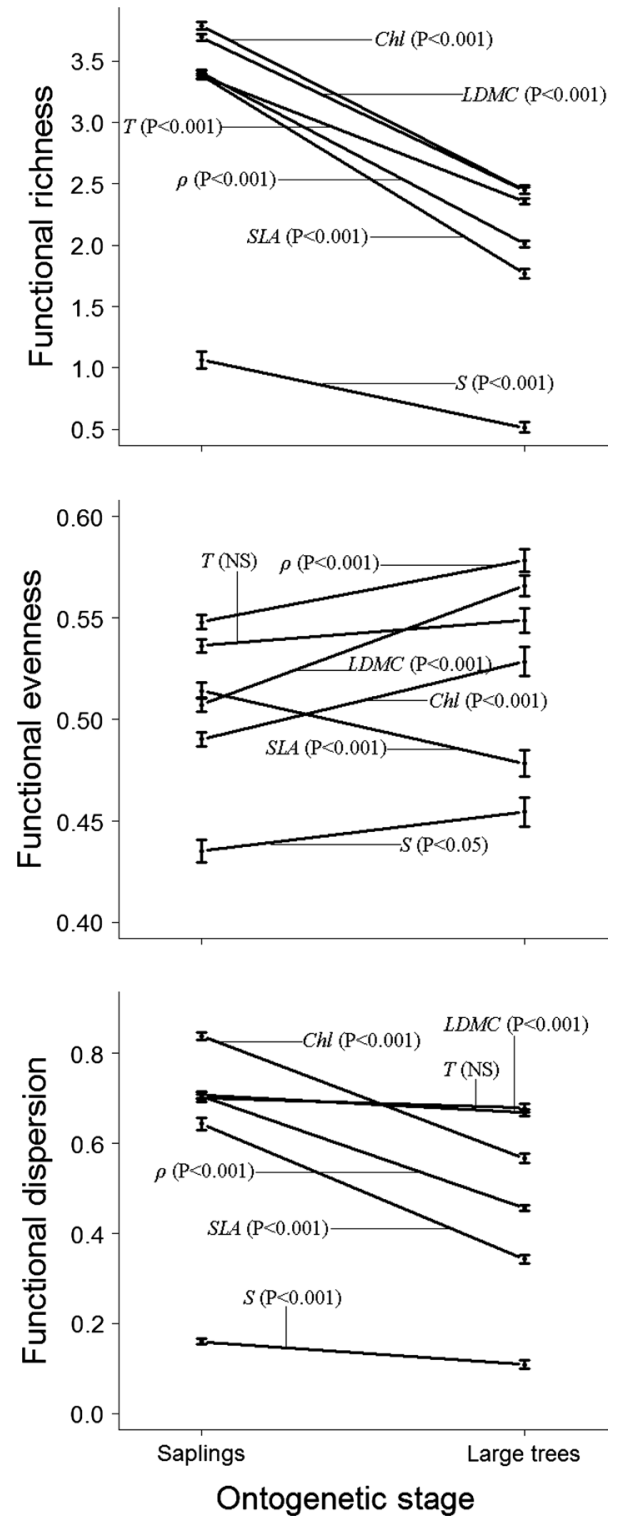

Fig. 4 Difference of indices of functional diversity (functional richness, evenness and dispersion) between saplings $(1 \leq$ diameter $\leq 5)$ and large trees $(10 \leq$ diameter $\leq 50)$ for single traits. NS, Not significant; see Fig. 1 for other abbreviations

diversity were significantly different when all traits were combined. Functional richness was significantly greater in saplings than large trees $(P<0.001)$, functional evenness was significantly greater in large trees than saplings $(P<0.001)$, and functional dispersion was significantly greater in saplings than large trees $(P<0.001)$.

\section{Discussion}

We evaluated the relative importance of functional traits and environment on tree growth, and sought to determine whether the influence of these factors on growth changed with ontogeny in subtropical tree species. Our results showed that different functional traits and environmental factors were important growth predictors in different stages, with sapling RGR more related to functional traits than soil environment, and large-tree RGR more related to soil environment than functional traits. We also measured decreasing functional diversity and functional dispersion, as well as increasing functional evenness as these tree communities transition from saplings to large trees. These results are consistent with the idea that large trees in tropical forest show greater associations between growth and environment than saplings because they have undergone a habitat filtering process that has eliminated individuals that were able to germinate in a site but were not well suited to local site conditions (Cornwell et al. 2006; Kraft et al. 2008; Webb and Peart 2000). This process is analogous to stabilizing selection at local scales and appears to result in communities of large trees that are more specialized to local site conditions than saplings, thus providing a mechanism for the observed ontogenetic variation in the factors that regulate RGR.

Our results showing that trait-RGR relationships were stronger for saplings than for large trees are consistent with previous reports (Hérault et al. 2011; Poorter et al. 2008; Wright et al. 2010). Traits such as $\rho$ and $H_{\max }$ were good predictors of RGR for saplings, likely because these traits integrate trade-offs between species with fast growth, low tissue density and high mortality rates, and species that have opposite traits (Alvarez-Clare and Kitajima 2007; Falster and Westoby 2005; Wright et al. 2010). Values for $\rho$ also incorporate information on hydraulic strategies because tropical tree species with low as $\rho$ tend to have higher rates stem hydraulic conductivity than high as $\rho$ species (Santiago et al. 2004a), yet incorporating explicit measurements of hydraulic traits into analyses of community structure are likely to illuminate new aspects of ecological strategies. We also noted that $S$ was important for RGR in saplings, consistent with the notion that light interception plays a much more important role in the growth of saplings than larger trees because thin and large leaves, in which biomass is spread across a greater surface area than in thick leaves, is advantageous for supporting higher growth rates (Lusk et al. 2008; Santiago and Wright 2007). These data also suggest that most individuals in the Dinghushan forest occur in the mid-canopy, sub-canopy or understory and relatively few individuals occur in full sunlight. The result that large-tree RGR was not strongly predicted by functional traits is likely due to lesser trait variation in largetree communities than among saplings, indicated by differences in functional richness, evenness and dispersion among ontogenetic stages. Because we used the same mean trait value for each species to evaluate relationships with 
growth, our differences with ontogeny demonstrate a narrowing of the existing physiological strategies in each subplot as the cohort matures, rather than reflecting the wellknown convergence of trait values with increasing tree size (Delagrange et al. 2004). Overall, our plant functional trait analysis represents at least three axes of ecological strategy variation, including the leaf economics spectrum (SLA, LDMC, $T, \mathrm{Chl}),\left(H_{\max } \rho\right)$, and $S$ (Westoby 1998; Westoby et al. 2002; Wright et al. 2004). Including other axes of ecological strategy variation, such as the seed size-output trade-off (Moles et al. 2005; Westoby et al. 2002), is likely to increase the resolution of trait-growth relationships.

RGRs of saplings and large trees were associated with distinct indices of fertility. For example, in single-variable correlation analysis, sapling RGR was enhanced with TK, $\mathrm{AK}$ and AP, whereas large-tree RGR was enhanced by OM, $\mathrm{AK}, \mathrm{TN}$ and AN. These results are consistent with multiple nutrient limitations, in which several elements interact or otherwise co-limit plant responses to alleviation of nutrient limitation (Bloom et al. 1985; Rubio et al. 2003). These results are also consistent with reports that trees in different growth stages can show contrasting growth responses to elemental availability. In lowland tropical forest in Panama, seedlings, saplings and poles increase growth rates when $\mathrm{N}$ and $\mathrm{K}$ limitations are alleviated by experimental nutrient addition, whereas large trees only respond to $\mathrm{P}$ addition (Santiago et al. 2012; Wright et al. 2011). Enhanced supplies of $\mathrm{N}, \mathrm{P}$ or $\mathrm{K}$ all have the potential to enhance growth because of their positive effects on photosynthetic productivity and activation of key enzymes necessary for efficient growth (Evans 1989; Pasquini and Santiago 2012). However, increased growth in large trees, but not in saplings, in response to environmental $\mathrm{N}$ availability suggests that the importance of $\mathrm{N}$ for carboxylation capacity increases with the elevated light availability of large trees. Interestingly, soil TP was inversely related with growth in large trees. Yet, AP was negatively correlated with soil $\mathrm{pH}(r=-0.69$; $P<0.001)$ and TP $(r=-0.59 ; P<0.001)$, suggesting that the negative effects of soil $\mathrm{pH}$ and $\mathrm{TP}$ are the result of secondary correlation with AP. Soil $\mathrm{pH}$ is critical for P availability because precipitation occurs in specific $\mathrm{pH}$ ranges (Lambers et al. 2008). Furthermore, AP can be negatively correlated with indices of unavailable soil $\mathrm{P}$ because factors such as poor litter quality can constrain available $\mathrm{P}$ during nutrient cycling in tropical soils (Santiago et al. 2005). Although we are comparing environment-RGR relationships among individuals that vary greatly in size using soil and topographical measurements that also vary across unknown scales, our results generate compelling hypotheses for linking soil environment to growth in subtropical tree species.

One striking result of this work is that in stepwise regression, topographic factors were related to RGR of large trees, but not saplings. This finding suggests that saplings are somewhat buffered from major landforms in terms of growth regulation. The single-factor negative correlation between convexity and sapling RGR is likely associated with greater moisture and nutrient accumulation in local lows. Convexity reflects the contrast in altitude between a focal quadrat and surrounding quadrats, where very high convexity may indicate a hilltop and very low convexity may indicate bottomlands or a local hollow. In saplings, low RGR at high convexity is probably associated with greater exposure to wind and weather, as well as greater run-off of water (Garciaoliva et al. 1995), whereas high RGR at low convexity is likely driven by soil factors. Thus, differences in how seedlings are buffered from topographical effects by closed-canopy forest conditions, and how large trees are exposed to the environment above the canopy also contribute to ontogenetic variation in the factors that control RGR.

Overall, our data indicate that variation in the factors that control RGR with ontogenetic stage is critical for interpreting and predicting growth patterns in tropical forests. Different functional traits and environmental factors had important effects on tree growth in different ontogenetic stages, indicating that trees have different growth strategies in different ontogenetic stages. However, traits and biomass allocation might change across ontogenetic stages and light gradients (Kohyama 1987, 1991; Kohyama and Grubb 1994; Delagrange et al. 2004), but this interaction is difficult to quantify in tropical forests. Incorporating ontogenetic stage into trait measurements, and including light effects, is likely to provide more information about RGR in future studies. We also found evidence of habitat filtering based on shifts in functional diversity, evenness and dispersion, as well as stronger relationships between RGR and environment in large trees than in saplings. Apparently sapling communities are considerably more random in their composition than large-tree communities. The findings are consistent with previous studies in the DHS plot, which have demonstrated species coexistence mechanisms through spatial distributions of tree species ( $\mathrm{Li}$ et al. 2009), intraspecific density-dependent mortality (Shen et al. 2013) and phylogenetic mechanisms (Pei et al. 2011). These findings also set the stage for future studies that will address how the seedling community is filtered into a large-tree community that reflects local habitat requirements, and which critical factors influence the pace of species filtering and promote species coexistence in diverse tropical forests.

Acknowledgments We thank Prof. Bai-lian Li for establishing collaborations between the University of California Riverside and the South China Botanical Garden; numerous individuals in South China Botanical Garden who contributed to the field survey of Dinghushan plot; and the Santiago Lab for comments that improved the manuscript. The study was funded by the National Natural Science 
Foundation of China (31370446, 31100312), the Knowledge Innovation Project of The Chinese Academy of Sciences (KSCX2-EW-Z), the Foreign Exchange Program National Founder (31011120470), the Chinese Forest Biodiversity Monitoring Network and the China Scholarship Council.

\section{References}

Alvarez-Clare S, Kitajima K (2007) Physical defence traits enhance seedling survival of Neotropical tree species. Funct Ecol 21:1044-1054

Bellingham PJ, Tanner EVJ (2000) The influence of topography on tree growth, mortality, and recruitment in a tropical montane forest. Biotropica 32:378-384

Bloom AJ, Chapin FS, Mooney HA (1985) Resource limitation in plants-an economic analogy. Annu Rev Ecol Syst 16:363-392

Carreno-Rocabado G, Pena-Claros M, Bongers F, Alarcon A, Licona JC, Poorter L (2012) Effects of disturbance intensity on species and functional diversity in a tropical forest. $\mathrm{J}$ Ecol 100:1453-1463

Chalmandrier L et al (2013) A family of null models to distinguish between environmental filtering and biotic interactions in functional diversity patterns. J Veg Sci 24:853-864

Chevan A, Sutherland M (1991) Hierarchical partitioning. Am Stat 45:90-96

Clark DA et al (2001) Net primary production in tropical forests: an evaluation and synthesis of existing field data. Ecol Appl 11:371-384

Comita LS, Engelbrecht BMJ (2009) Seasonal and spatial variation in water availability drive habitat associations in a tropical forest. Ecology 90:2755-2765

Condit R, Hubbell SP, Foster RB (1995) Mortality-rates of 205 Neotropical tree and shrub species and the impact of a severe drought. Ecol Monogr 65:419-439

Cornelissen JHC et al (2003) A handbook of protocols for standardised and easy measurement of plant functional traits worldwide. Aust J Bot 51:335-380

Cornwell WK, Schwilk DW, Ackerly DD (2006) A trait-based test for habitat filtering: convex hull volume. Ecology 87:1465-1471

Delagrange S, Messier C, Lechowicz MJ, Dizengremel P (2004) Physiological, morphological and allocational plasticity in understory deciduous trees: importance of plant size and light availability. Tree Physiol 24:775-784

Ehrenfeld JG, Ravit B, Elgersma K (2005) Feedback in the plant-soil system. Annu Rev Environ Resour 30:75-115

Enquist BJ, Kerkhoff AJ, Stark SC, Swenson NG, McCarthy MC, Price CA (2007) A general integrative model for scaling plant growth, carbon flux, and functional trait spectra. Nature 449:218-222

Evans JR (1989) Photosynthesis and nitrogen relationships in leaves of C-3 plants. Oecologia 78:9-19

Falster DS, Westoby M (2005) Alternative height strategies among 45 dicot rain forest species from tropical Queensland, Australia. J Ecol 93:521-535

Fisher JB et al (2013) Nutrient limitation in rainforests and cloud forests along a 3,000-m elevation gradient in the Peruvian Andes. Oecologia 172:889-902

Garciaoliva F, Maass JM, Galicia L (1995) Rainstorm analysis and rainfall erosivity of a seasonal tropical region with a strong cyclonic influence on the Pacific Coast of Mexico. J Appl Meteorol 34:2491-2498

Grime JP (1977) Evidence for existence of 3 primary strategies in plants and its relevance to ecological and evolutionary theory. Am Nat 111:1169-1194
Gromping U (2006) Relative importance for linear regression in R: the package relaimpo. J Stat Softw 17

Harms KE, Condit R, Hubbell SP, Foster RB (2001) Habitat associations of trees and shrubs in a 50-ha Neotropical forest plot. J Ecol 89:947-959

Hérault B et al (2011) Functional traits shape ontogenetic growth trajectories of rain forest tree species. J Ecol 99:1431-1440

Kohyama T (1987) Significance of architecture and allometry in saplings. Funct Ecol 1:399-404

Kohyama T (1991) A functional-model describing sapling growth under a tropical forest canopy. Funct Ecol 5:83-90

Kohyama T, Grubb PJ (1994) Belowground and aboveground allometries of shade-tolerant seedlings in a Japanese warm temperate rain-forest. Funct Ecol 8:229-236

Kraft NJB, Valencia R, Ackerly DD (2008) Functional traits and niche-based tree community assembly in an Amazonian forest. Science 322:580-582

Laliberte E, Legendre P (2010) A distance-based framework for measuring functional diversity from multiple traits. Ecology 91:299-305

Lambers H, Chapin SF III, Pons TL (2008) Plant physiological ecology. Springer, New York

Legendre P et al (2009) Partitioning beta diversity in a subtropical broad-leaved forest of China. Ecology 90:663-674

Li L et al (2009) Spatial distributions of tree species in a subtropical forest of China. Oikos 118:495-502

Lin GJ, Stralberg D, Gong GQ, Huang ZL, Ye WH, Wu LF (2013) Separating the effects of environment and space on tree species distribution: from population to community. PLoS One 8:e56171

Loh FCW, Grabosky JC, Bassuk NL (2002) Using the SPAD 502 meter to assess chlorophyll and nitrogen content of benjamin fig and cottonwood leaves. Horttechnology 12:682-686

Lusk CH, Reich PB, Montgomery RA, Ackerly DD, Cavender-Bares J (2008) Why are evergreen leaves so contrary about shade? Trends Ecol Evol 23:299-303

Mac Nally R (2002) Multiple regression and inference in ecology and conservation biology: further comments on identifying important predictor variables. Biodivers Conserv 11:1397-1401

Martíne-Vilalta J, Pinol J, Beven K (2002) A hydraulic model to predict drought-induced mortality in woody plants: an application to climate change in the Mediterranean. Ecol Model 155:127-147

Martínez-Vilalta J, Mencuccini M, Vayreda J, Retana J (2010) Interspecific variation in functional traits, not climatic differences among species ranges, determines demographic rates across 44 temperate and Mediterranean tree species. J Ecol 98:1462-1475

Mason NWH, Mouillot D, Lee WG, Wilson JB (2005) Functional richness, functional evenness and functional divergence: the primary components of functional diversity. Oikos 111:112-118

McMahon SM, Metcalf CJE, Woodall CW (2011) High-dimensional coexistence of temperate tree species: functional traits, demographic rates, life-history stages, and their physical context. PLoS One 6:e16253

Moles AT, Ackerly DD, Webb CO, Tweddle JC, Dickie JB, Westoby M (2005) A brief history of seed size. Science 307:576-580

Palmiotto PA, Davies SJ, Vogt KA, Ashton MS, Vogt DJ, Ashton PS (2004) Soil-related habitat specialization in dipterocarp rain forest tree species in Borneo. J Ecol 92:609-623

Pasquini SC, Santiago LS (2012) Nutrients limit photosynthesis in seedlings of a lowland tropical forest tree species. Oecologia 168:311-319

Pei NC et al (2011) Exploring tree-habitat associations in a Chinese subtropical forest plot using a molecular phylogeny generated from DNA barcode loci. PLoS One 6:e21273

Pockman WT, Sperry JS (2000) Vulnerability to xylem cavitation and the distribution of Sonoran desert vegetation. Am J Bot $87: 1287-1299$ 
Poorter L et al (2008) Are functional traits good predictors of demographic rates? Evidence from five Neotropical forests. Ecology 89:1908-1920

Reich PB, Walters MB, Ellsworth DS (1997) From tropics to tundra: global convergence in plant functioning. Proc Natl Acad Sci USA 94:13730-13734

Rubio G, Zhu JM, Lynch JP (2003) A critical test of the two prevailing theories of plant response to nutrient availability. Am J Bot 90:143-152

Russo SE, Davies SJ, King DA, Tan S (2005) Soil-related performance variation and distributions of tree species in a Bornean rain forest. J Ecol 93:879-889

Santiago LS, Wright SJ (2007) Leaf functional traits of tropical forest plants in relation to growth form. Funct Ecol 21:19-27

Santiago LS et al (2004a) Leaf photosynthetic traits scale with hydraulic conductivity and wood density in Panamanian forest canopy trees. Oecologia 140:543-550

Santiago LS, Kitajima K, Wright SJ, Mulkey SS (2004b) Coordinated changes in photosynthesis, water relations and leaf nutritional traits of canopy trees along a precipitation gradient in lowland tropical forest. Oecologia 139:495-502

Santiago LS, Schuur EAG, Silvera K (2005) Nutrient cycling and plant-soil feedbacks along a precipitation gradient in lowland Panama. J Trop Ecol 21:461-470

Santiago LS et al (2012) Tropical tree seedling growth responses to nitrogen, phosphorus and potassium addition. J Ecol 100:309-316

Shen Y et al (2013) Forest dynamics of a subtropical monsoon forest in Dinghushan, China: recruitment, mortality and the pace of community change. J Trop Ecol 29:131-145

Spasojevic MJ, Suding KN (2012) Inferring community assembly mechanisms from functional diversity patterns: the importance of multiple assembly processes. J Ecol 100:652-661
Sterck F, Markesteijn L, Schieving F, Poorter L (2011) Functional traits determine trade-offs and niches in a tropical forest community. P Natl Acad Sci USA 108:20627-20632

Tsujino R, Takafumi H, Agetsuma N, Yumoto T (2006) Variation in tree growth, mortality and recruitment among topographic positions in a warm temperate forest. J Veg Sci 17:281-290

Villeger S, Mason NWH, Mouillot D (2008) New multidimensional functional diversity indices for a multifaceted framework in functional ecology. Ecology 89:2290-2301

Violle C et al (2007) Let the concept of trait be functional! Oikos 116:882-892

Vitousek PM (2004) Nutrient cycling and limitation: Hawai'i as a model system. Princeton University Press, Princeton

Webb CO, Peart DR (2000) Habitat associations of trees and seedlings in a Bornean rain forest. J Ecol 88:464-478

Westoby M (1998) A leaf-height-seed (LHS) plant ecology strategy scheme. Plant Soil 199:213-227

Westoby M, Falster DS, Moles AT, Vesk PA, Wright IJ (2002) Plant ecological strategies: some leading dimensions of variation between species. Annu Rev Ecol Syst 33:125-159

Wright IJ et al (2004) The worldwide leaf economics spectrum. Nature 428:821-827

Wright SJ et al (2010) Functional traits and the growth-mortality trade-off in tropical trees. Ecology 91:3664-3674

Wright SJ et al (2011) Potassium, phosphorus, or nitrogen limit root allocation, tree growth, or litter production in a lowland tropical forest. Ecology 92:1616-1625

Ye WH et al (2008) Community structure of a 20 ha lower subtropical evergreen broadleaved forest plot in Dinghushan, China (in Chinese with English abstract). J Plant Ecol 32:274-286 